Revista do Departamento de Geografia
Universidade de São Paulo
www.revistas.usp.br/rdg

\title{
O Controle da Flora e Fauna Aquáticas pela Resolução CONAMA 467: Considerações Sobre a Normativa Brasileira
}

\author{
The Control of Flora and Aquatic Fauna by CONAMA Resolution 467: \\ Considerations on Brazilian Regulation
}

\author{
Marcelo Pompêo \\ Universidade de São Paulo \\ mpompeo@ib.usp.br
}

Recebido (Received): 20/09/2016 DOI: $10.11606 /$ rdg.v33i0.121065

Aceito (Accepted): 20/12/2016

Resumo: O monitoramento e manejo de organismos aquáticos é fundamental para garantir a sustentabilidade dos corpos de água doce, em particular dos reservatórios. Há normativas relacionadas à obrigatoriedade do monitoramento das cianobactérias e coliformes, mas não de macrófitas aquáticas no Brasil. Cabe a um plano de monitoramento acompanhar as alterações na qualidade da água e do sedimento, e a um plano de manejo as ações práticas necessárias para que possam ser garantidas a qualidade dos usos atuais e futuros de um dado reservatório. Este manuscrito apresenta análise crítica à proposta de manejo de organismos aquáticos disciplinada pela Resolução CONAMA 467, de 17 de julho de 2015, que dispõe sobre os critérios para a autorização de uso de produtos ou de agentes de processos físicos, químicos ou biológicos em corpos hídricos superficiais para controle da poluição e do crescimento desordenado ou indesejável de organismos da flora e da fauna e dá outras providências. Entre outras considerações, com base na análise apresentada, conclui-se que esta Resolução apenas reforçará o manejo da biota principalmente pelo emprego de compostos químicos, num ciclo vicioso contínuo de manejos e crescimentos descontrolados recorrentes, visto não disciplinar a atuação de modo preventivo e autosustentável, disciplinando a coleta e o tratamento dos esgotos, os verdadeiros responsáveis pela entrada de nutrientes e pelo processo de eutrofização e, consequentemente, do crescimento explosivo das algas ou de macrófitas aquáticas.

Palavras-chave: Manejo, Qualidade da Água, Qualidade do Sedimento.

\begin{abstract}
The monitoring and management of aquatic organisms is critical to ensure the sustainability of freshwater bodies, particularly the reservoirs. There are regulations related to mandatory monitoring of some aquatic organisms in Brazil, especially cyanobacteria and coliforms, but not of macrophytes. Monitoring and management plans are both required, respectively, to track changes in water and sediment quality and to plan actions to ensure the reservoir's current and future quality. This paper aims to present a critical analysis of the aquatic organisms' management proposal stated by CONAMA Resolution 467 (July 17, 2015). This Resolution states about criteria for the authorization of the use of products or physical, chemical or biological agents on water bodies' surface to control pollution and the extreme growth of flora and fauna organisms, and other measures. Among other considerations, based on the presented analysis, it is concluded that this Resolution reinforces biota management through the use of chemical compounds, in a continuous vicious cycle of management and recurrent uncontrolled growth of organisms, since it does not state preventive and self-sustaining management, for instance, through sewage collection and treatment. Such measure would deal with the main causes of nutrients input and eutrophication, consequently, of explosive growth of algae and macrophytes.
\end{abstract}

Keywords: Management, Water Quality, Sediment Quality 


\section{INTRODUÇÃO}

Estimativas do Banco Mundial mostram que nos países em desenvolvimento os gastos correntes com água e saneamento estão na ordem de aproximadamente US\$ 28 bilhões por ano (SELBORNE, 2001). Segundo esse autor, quando esse montante não é aplicado, os demais custos implicados são reais, mas ocultos, e representam cerca de três vezes esse valor, só em termos de saúde e doença. Segue comentando que no mundo em desenvolvimento, $90 \%$ das doenças estão relacionadas com a qualidade das águas. Selborne (2001) discorre que os sistemas de saneamento básico podem reduzir de $20 \%$ a $80 \%$ a incidência de doenças infecciosas, inibindo a sua geração e interrompendo a sua transmissão. Manter a água e o sedimento dos reservatórios em bons potenciais químico e ecológico, ou seja, em condições em que os impactos antrópicos sejam mínimos, como preconiza a Diretiva Quadro da Água (DQA), normativa da Comunidade Europeia (EC, 2000; MOSS, 2008; CARDOSO-SILVA et al. 2013), não só nos garantirá água de qualidade para o futuro, com sustentabilidade, mas contribuirá com melhores padrões de saúde para a população e reduzirá os riscos de doenças diversas.

Deste modo, a aplicação de programas de monitoramento e manejo das águas e do sedimento são fundamentais para atingir bons padrões de qualidade e a sustentabilidade, em particular dos reservatórios, principalmente daqueles mais impactados, normalmente localizados próximos aos grandes centros urbanos, como os reservatórios Guarapiranga e o Complexo Billings, ambos vizinhos à cidade de São Paulo (Brasil), por exemplo. Estes programas também deverão permitir a manutenção de um ambiente saudável, sem significativas reduções na qualidade das águas e sedimentos, com seus níveis sempre dentro de aceitáveis padrões de qualidade, além de manter a qualidade e a intensidade de seus inúmeros usos múltiplos. O monitoramento e manejo devem direcionar ações que permitam manter ou não os usos atuais e futuros, alterando rumos sempre que ocorrer perda de qualidade nos serviços ecossistêmicos oferecidos pelo reservatório, na tentativa da manutenção da sustentabilidade ambiental. Portanto, cabe a um sólido plano de monitoramento (premissas pré-estabelecidas que regem o acompanhamento periódico realizado através de observações de diversos atributos ambientais e das comunidades biológicas do reservatório, indicadores do funcionamento e da dinâmica e qualidade de um ecossistema, com base em teorias ecológicas), acompanhar as alterações na qualidade das águas e do sedimento; e a um plano de manejo (as premissas pré-estabelecidas que regem as ações de controle dos atributos ambientais ou das comunidades biológicas, visando atingir um objetivo definido), as ações práticas para que possam ser garantidas a qualidade dos usos atuais e futuros de um reservatório.

Este manuscrito visa apresentar análise crítica à proposta de manejo das massas de água para o controle de organismo aquáticos considerados indesejados a alguém ou a algum uso, disciplinada pela Resolução CONAMA 467, de 2015, mas com ênfase na aplicação de produtos ou de agentes de processos químicos. Como a Resolução não reforça a coleta e o tratamento dos efluentes e nem mesmo o monitoramento e o manejo preventivos, por permitir a aplicação de compostos químicos para o controle dos organismos indesejados, sua redação permite concluir que também potencializará as já más qualidades da água e do sedimento e o desequilíbrio da biota, como será mostrado.

\section{MONITORAMENTO E MANEJO}

No Brasil há legislação que obriga o monitoramento de cianobactérias e de coliformes (CONAMA 357/2005, CONAMA 247/2000; Portaria MS n. 2.914/2011 - Brasil, 2011). No caso dos coliformes, o monitoramento visa evitar a contaminação no abastecimento público e garantir segurança no contato primário, principalmente. No caso das cianobactérias, a Portaria "se aplica à água destinada ao consumo humano proveniente de sistema e solução alternativa de abastecimento de água", com a finalidade maior de acompanhar o desenvolvimento de organismos potencialmente tóxicos, particularmente as cianobactérias. Mas diferentemente do olhar meramente utilitarista do recurso hídrico, é importante aplicar uma abordagem ecológica tanto no monitoramento como no manejo, visto as interações que ocorrem entre todos os componentes do ecossistema, a biota e o meio físico, pois, como apontado por Straškraba \& Tundisi, (2000), a conservação da qualidade e quantidade das águas de reservatórios é um problema complexo e que demandará um conhecimento científico integrado e interdisciplinar. Esta visão ecológica permitirá integrar todos os componentes e compartimentos do ecossistema, e não apenas um aspecto, o controle do crescimento de cianobactérias, por exemplo, o que garantirá sustentabilidade ambiental no longo prazo. Nesse sentido, as normativas que preconizam o monitoramento e manejo visando a manutenção dos bons potenciais químico e ecológico de reservatórios, segundo a DQA, por exemplo (EC, 2000; MOSS, 2008; CARDOSO-SILVA et 
al. 2013), são muito promissoras e inovadoras. Já relativo às macrófitas aquáticas, não há normativa específica que discipline seu monitoramento no Brasil.

Há algumas experiências brasileiras no controle do crescimento de macrófitas aquáticas, mas principalmente por processos físicos (POMPÊO, 1999, 2008; ANDRADE, 2009). Sem dúvida, a maior experiência está no controle do crescimento de algas, em especial para alguns reservatórios paulistas, pela aplicação de controle químico. No reservatório Guarapiranga e no braço Rio Grande (Complexo Billings), há cerca de 43 anos é aplicado o sulfato de cobre pentahidratado para o controle de cianobactérias (MANCUSO, 1987; CALEFFI, 2000; CETESB, 2008), mas a partir de 1993 passou a ser amplamente empregado de modo intercalado ao sulfato de cobre o peróxido de hidrogênio $50 \%$ (ROCHA et al. sem data). Já o fluridone é o único agrotóxico aprovado pela Anvisa (Agência de Vigilância Sanitária) para aplicação em ambientes aquáticos no controle de macrófitas aquáticas das espécies Egeria densa e Egeria najas em reservatórios de hidrelétricas (ANVISA, sem data).

Apenas em 2008 o CONAMA (Conselho Nacional de Meio Ambiente) iniciou discussão de ampla Proposta de Resolução sobre a pesquisa, o registro, a comercialização e a utilização de agrotóxicos e afins em ambientes hídricos dando também outras providências (CONAMA, 2009). Esta Proposta de Resolução tinha como objetivo autorizar a atividade de controle de espécies aquáticas com compostos químicos, visando "alterar a composição ou densidade de uma ou mais espécies da flora ou fauna", tal como o fitoplâncton, por exemplo. Considerações contrárias acerca desta proposta de resolução foram apresentadas por Pompêo (2009) e pela Associação Brasileira de Limnologia (ABLIMNO, 2009). A CONAMA (2009) foi desconsiderada, mas em seu lugar foi publicada a CONAMA 467.

\section{A RESOLUÇÃO CONAMA 467}

Em 17 de julho de 2015 foi publicado no Diário Oficial da União (pag. 70) a Resolução CONAMA 467, que "dispõe sobre critérios para a autorização de uso de produtos ou de agentes de processos físicos, químicos ou biológicos em corpos hídricos superficiais para controle da poluição e do crescimento desordenado ou indesejável de organismos da flora e da fauna" e "dá outras providências". Ampla como a proposta de resolução anterior, a CONAMA (2009), a CONAMA 467 principalmente versa sobre a aplicação de compostos químicos para o controle dos organismos aquáticos. Ela não discrimina se a flora ou fauna a ser eventualmente controlada é nativa ou introduzida, definindo como meta, o controle de qualquer organismo. Esta Resolução abre a possibilidade de ampliar a aplicação de compostos químicos a todos os corpos de água brasileiros, como já ocorre rotineiramente há cerca de 40 anos com o sulfato de cobre e de 23 anos com o peróxido de hidrogênio, particularmente em reservatórios paulistas (MANCUSO, 1987; CALEFFI, 2000; CETESB, 2008; ROCHA et al. sem data), como já comentado, ou mesmo mais recentemente pela implantação de sistemas que combinem técnicas de flotação e remoção de flutuantes (KAKINAMI, 2004; FCTH, sem data), este último como alternativa às tradicionais estações de tratamento de esgotos (ETEs).

A redação da CONAMA 467 não permite vislumbrar a solução de problemas ao nível da bacia hidrográfica, com o controle dos usos e ocupações dos espaços e coletar e tratar 100\% os esgotos domésticos e industriais (POMPÊO $E$ MOSCHINI-CARLOS, 2012; POMPÊO $E$ MOSCHINI-CARLOS, 2015), segundo esses autores, consideradas as principais causas da grande entrada de nutrientes e pelo processo de eutrofização e, consequentemente, do excessivo crescimento de algas e de macrófitas aquáticas a ser controlado pela Resolução.

Vale reforçar que a CONAMA 467 não discorre sobre o monitoramento em si da espécie considerada problema, apesar do Art. 60 apresentar considerações a respeito do monitoramento e manejo. Assim, esta Resolução não privilegia um amplo processo de gestão, apenas fortalece o final dele, particularmente o controle do crescimento dos organismos (fauna ou flora, nativa ou introduzida) considerados indesejáveis a alguém ou a algum uso pelo homem. Como redigida a Resolução passa a ideia que será empregada após o problema instalado, quando autorizará a aplicação de químicos, reforçando o controle químico corretivo, por exemplo, e não os passos anteriores como o manejo preventivo, menos impactante.

O monitoramento ambiental, inserido num programa de gestão da qualidade das águas e das comunidades constituintes do reservatório, tem que ser entendido como um passo essencial e anterior ao próprio manejo, pois espera-se que estudos prévios, decorrentes da contínua avaliação a campo (o monitoramento), melhor disciplinem as tomadas de decisões para as ações de controle e a própria aplicação de agentes físicos, químicos ou biológicos (o manejo) no controle do crescimento de qualquer outro organismo aquático, 
conforme preconiza a CONAMA 467, se necessário e provado a sua eficácia (POMPÊO, 2017). Além disso, segundo esse autor, é fundamental a continuidade do monitoramento após tomadas as medidas de controle, como um mecanismo de feedback, permitindo acompanhar sua efetividade e seu impacto no corpo d'água e sobre os organismos, as espécies alvo e não alvo da ação de controle e, com base nos acontecimentos futuros, decidir se serão aplicadas novas medidas corretivas ou paliativas, se necessárias. Ainda segundo Pompêo (2017), devido aos múltiplos interesses e usos do reservatório, no plano de manejo deve haver clara previsão sobre os impactos que o manejo pretendido trará aos demais interesses, usos e usuários do reservatório. Também é importante que claramente sejam explicitadas as motivações do controle, se de fato ele é necessário, se será esporádico ou permanente, e que não ficasse restrito à apresentação de um único método de controle, principalmente o químico (POMPÊO, op cit.). A sugestão de outros procedimentos alternativos e seus prováveis impactos futuros e custos associados, auxiliam na tomada de decisão acerca do melhor procedimento a ser aplicado. Pompêo complementa que é fundamental explicitar quais usos do reservatório estão de fato prejudicados pelo intenso crescimento do organismo, como o fitoplâncton, e em que proporção e quais usos múltiplos seriam beneficiados pelos métodos de controle sugeridos. Independente de tudo, as técnicas de controle sugeridas devem ser adequadas ao organismo alvo. No caso das macrófitas aquáticas é importante considerar o biotipo, se é submersa fixa ou flutuante livre, por exemplo. Espera-se também que o manejo proposto impacte minimamente os demais usos e funções do corpo d'água (DI NINO et al. 2005), no sentido de construir estratégias técnica e economicamente factíveis (GUTIÉRREZ et al. 1996), ambientalmente saudáveis e autossustentáveis.

Ainda relativo à Resolução CONAMA 467, como há expressivos lançamentos de esgotos in natura nos corpos de água, como observado na Região Metropolitana de São Paulo (CETESB, 2011; POMPÊO E MOSCHINI-CARLOS, 2012), estes lançamentos se enquadrariam na categoria "emprego de produtos ou de agentes de processos físicos, químicos ou biológicos em corpos hídricos superficiais para controle da poluição e do crescimento desordenado ou indesejável de organismos da flora ou fauna", como apresentado no caput desta Resolução, já que são os principais "descontroladores" do crescimento vegetal. Neste caso, os lançamentos de esgoto bruto em fontes pontuais, principalmente, conforme o Art. 10 da própria CONAMA 467, inciso II, também deveriam ser avaliados pelos órgãos ambientais para autorização de uso/lançamento visando o "controle de poluição em corpos hídricos". Os nutrientes presentes nesses lançamentos de esgotos in natura são os agentes causadores da eutrofização e suas consequências previsíveis (VALLENTYNE, 1978; GOLDMAN E HORNE, 1983; HENDERSON-SELLERS E MARKLAND, 1987), como o excessivo crescimento das cianobactérias potencialmente tóxicas, e das macrófitas aquáticas, por exemplo. Portanto, esgoto coletado e não tratado, após a publicação da CONAMA 467, para ser lançado em dado manancial também deveria passar pelo crivo e autorização dos órgãos ambientais, conforme definido na própria Resolução, visando impedir o crescimento de organismos indesejáveis, objeto das ações da própria norma. Caso esse controle de fato ocorresse, não haveria a necessidade de contornar os efeitos da eutrofização e o excesso de macrófitas aquáticas ou de cianobactérias em crescimento, com mais um lançamento, desta vez de compostos químicos, por exemplo, que comprometem os usos múltiplos dos reservatórios, pois bastaria restringir a carga orgânica de nutrientes lançada no reservatório previamente tratando os esgotos (POMPÊO, 2017).

Com base na redação da Resolução CONAMA 467 é possível compreender que não haverá intervenção na causa do problema, a grande entrada de nutrientes nos reservatórios e a consequente eutrofização e o excessivo crescimento vegetal. Deste modo, para conter o crescimento excessivo, há a aplicação da própria CONAMA 467, que permitirá lançar diferentes compostos químicos, o que no mínimo é contraditório, contraproducente e não autossustentável (POMPÊO, 2017). Ao não se tratar os esgotos e serem mantidas altas cargas de nutrientes que entram no reservatório, rotineiramente novas explosões de crescimento de macrófitas aquáticas e fitoplâncton devem ocorrer. Deste modo, também novas aplicações de compostos químicos ou outros processos físicos e biológicos poderão ser necessários, mantendo o processo num ciclo vicioso contínuo de manejos e crescimentos descontrolados recorrentes. Isso ocorre nos reservatórios Guarapiranga e no braço Rio Grande (Complexo Billings), representando um questionável programa de manejo para o controle do crescimento fitoplanctônico (LEAL, 2017) há 43 anos definido por regulares aplicações de sulfato de cobre e por 23 anos de peróxido de hidrogênio (CALEFFI, 2000; ROCHA et al., sem data), como já comentado. A continuidade na entrada de elevada carga de nutrientes permite concluir que no reservatório Guarapiranga por muitos anos ainda serão mantidas como rotina as constantes aplicações de sulfato de cobre nesse reservatório. Esse padrão de manejo, agora nacionalmente reforçado pela publicação da CONAMA 467, não disciplina a atuação de modo preventivo e autossustentável, com base nos princípios de um programa de gestão pré-concebido, por exemplo, definindo como prioritário a coleta e o tratamento dos esgotos, reduzindo o impacto do processo de eutrofização. 
Mas o controle da eutrofização é factível e há caso de sucesso no Brasil. Angelini et al. (2008) demonstram que no Lago Paranoá (Brasília, DF) as rotineiras florações algais somente foram significativamente reduzidas após a operação de uma ETE e do procedimento de flushing, com a liberação da carga de fundo, reduzindo o estoque de fósforo no reservatório. Em menos de dez anos após a efetiva instalação e operação da ETE, complementado pelo flushing, as concentrações de fósforo total e de clorofila a reduziram significativamente enquanto que saltaram as profundidades do disco de Sechhi. Portanto, alternativa há à aplicação regular de compostos químicos. Também há competência técnica no Brasil para construir e operar uma ETE, basta a decisão política para que de fato saia do papel.

Para a CONAMA 467 também valem as considerações apresentadas em Pompêo (2009) e ABLimno (2009), relacionadas ao impacto do controle do crescimento dos organismos aquáticos por meio de compostos químicos.

Já Berti (2013), por meio da interpolação de dados, construiu matrizes de interação visando analisar o grau de impacto em função do uso de diversos métodos de controle de macrófitas em reservatórios, comparando os valores do Índice de Caso de Referência (ICR) obtidos para cada aspecto. Berti concluiu que o método de controle menos impactante às macrófitas aquáticas é o biológico, embora apresente como desvantagem a necessidade de um controle rigoroso da introdução de uma nova espécie no meio. Segundo essa autora, o método de controle mais impactante foi o químico, cujos impactos negativos na fauna e na flora superaram os impactos dos demais métodos analisados, além de ser prejudicial para o aspecto da qualidade da água em longo prazo. A autora concluiu que os demais métodos estudados se equivalem nos impactos ambientais na água, flora e fauna aquáticas.

\section{O SULFATO DE COBRE E O PERÓXIDO DE HIDROGÊNIO COMO ALGICIDAS}

Para se ter ideia do que representam as aplicações de sulfato de cobre para a qualidade do sedimento, seguem algumas considerações sobre seu emprego como algicida em reservatórios paulistas.

Referentes aos anos de 2005 a 2008, nos relatórios de qualidade das águas interiores produzidos pela CETESB (Companhia Ambiental do Estado de São Paulo), há observações relacionadas ao sulfato de cobre, particularmente para os reservatórios com constantes aplicações desse composto (Tabela 1). Como o sulfato de cobre tem ação bactericida, esses relatórios de qualidade das águas interiores sugerem que esse composto possa interferir positivamente nos valores de coliformes determinados. Além do mais, sua ação algicida, como é de se esperar, não permite que os teores de clorofila determinados sejam compatíveis com os teores de fósforo presentes sendo, portanto, muitas vezes, subestimados (POMPÊO et al., 2015).

Por conta do uso do algicida sulfato de cobre para o controle de algas, mas também decorrente das constantes aplicações, os reservatórios listados na Tabela 1 têm elevados teores de cobre na água (CETESB, 2009). Mas mesmo com a ampla utilização de algicidas, há aumento da densidade de organismos da comunidade fitoplanctônica nos reservatórios Guarapiranga e Jundiaí (CETESB op cit.). Assim como no reservatório Billings (braço Taquacetuba), o número de células de cianobactérias permaneceu elevado nos reservatórios Rio Grande e Guarapiranga. Mesmo que as concentrações algais observadas fossem baixas elas são irreais, mantidas de modo artificial por conta das regulares aplicações de algicidas. Ainda Cetesb (op cit.) relata que as concentrações de cobre nos sedimentos do reservatório Rio Grande próximo à zona da barragem, e de captação de água bruta na estação de coleta RGDE 02900, permaneceram significativamente elevadas, cerca de 16 vezes superior a PEL (Probable Effect Levels, CCME, 2003), como também observado por Mariani (2010), Mariani e Pompêo (2008) nesse braço e por Pompêo et al. (2013) (Figura 1) e Leal (2017) no sedimento do reservatório Guarapiranga. Vale reforçar que concentrações acima do valor de referência (PEL) sugerem toxicidade provável do sedimento para a biota. $\mathrm{O}$ aumento da densidade de cianobactérias, como observado nos reservatórios Guarapiranga e Jundiaí (CETESB, op cit.), particularmente onde há maior acúmulo de cobre, segundo Beghelli et al. (2015), sugere adaptação da comunidade ao algicida, como comentado por Hanson e Stefan (1984), Mancuso (1987) e Raman e Cook (1988). Além disso, no reservatório Guarapiranga, Beghelli et al. (op cit.) também sugerem que espécies zooplanctônicas não alvo foram afetadas pelo algicida, já comentado por Caleffi (2000). 
Tabela 1: Aplicação anual de sulfato de cobre nas represas Jundiaí, Guarapiranga e Billings (braço Rio Grande) nos anos de 2005 a 2008 e mês (entre parêntesis) com pico de aplicação no ano de referência. Modificado de CETESB (2006, 2007, 2008 e 2009). Dados fornecidos pela SABESP (Companhia de Saneamento Básico do Estado de São Paulo).

\begin{tabular}{c|c|c|c|c|c}
\hline \multirow{2}{*}{ Represa } & \multicolumn{4}{|c|}{ ano de aplicação - Toneladas ${ }^{(*)}$} & Total \\
\cline { 2 - 6 } & 2005 & 2006 & 2007 & 2008 & \\
\hline Jundiaí & & $<20$ & 42 & 350 & 1140 \\
\hline Guarapiranga & & 350 & 440 & & 510 \\
\hline Rio Grande & & 150 & 360 & & 1712 \\
\hline total & & 5 (outubro) & 16 (dezembro) & & \\
\hline Jundiaí & & $>60$ (janeiro) & 76 (setembro) & 70 (dezembro) & \\
\hline Guarapiranga & 49 (novembro) & 44 (março) & 62 (agosto) & & \\
\hline Rio Grande & & &
\end{tabular}

(*) valores estimados, retirados de gráficos.

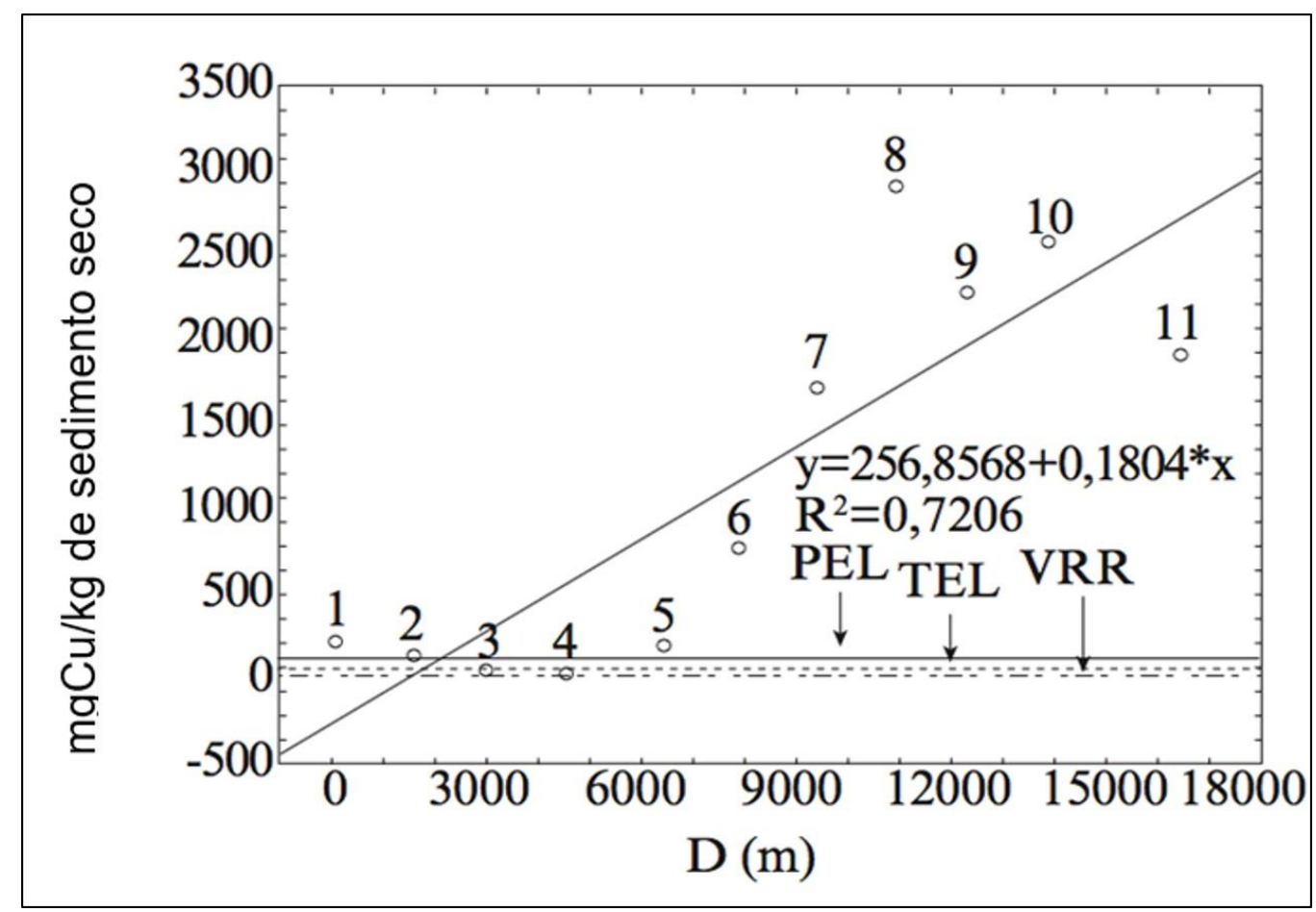

Figura 1: Concentrações de $\mathrm{Cu}$ no sedimento de 11 pontos de coleta no reservatório Guarapiranga, em 05/10/2006. PEL: Probable Effect Level (efeito provável); VRR: valores de referência regionais; TEL: Threshold Effect Level (efeito limiar); D: distância em relação ao ponto de origem (ponto 1). Segundo Pompêo et al. (2013).

Visando controlar o crescimento de organismos fitoplanctônicos, no ano de 2008 foram aplicadas cerca de 350 toneladas de sulfato de cobre no reservatório Guarapiranga, mas apenas para o mês de dezembro de 2008 a aplicação atingiu a marca de 70 toneladas de sulfato de cobre (Tabela 1). No braço Rio Grande (Complexo Billings), nos meses de janeiro, março, abril e novembro, os valores de sulfato de cobre aplicados ficaram em torno de 50 toneladas em 2004, enquanto, em 2005, ficaram abaixo de 20 toneladas (CETESB, 2006). Para o Guarapiranga, a aplicação de sulfato de cobre variou mensalmente entre 8 (setembro) a 49 toneladas (novembro) em 2005, valores considerados semelhantes ao aplicado no ano de 2004. Para os anos de 2006 e 2007, aplicações significativas de sulfato de cobre ocorreram no braço Rio Grande e Guarapiranga (Tabela 1). Mais recentemente, no reservatório Paiva Castro (Mairiporã, São Paulo), as aplicações ocorrem principalmente no verão, e já são refletidos nos teores de cobre do sedimento mais superficial do reservatório (CARDOSO-SILVA et al., 2016) (Figura 2). 


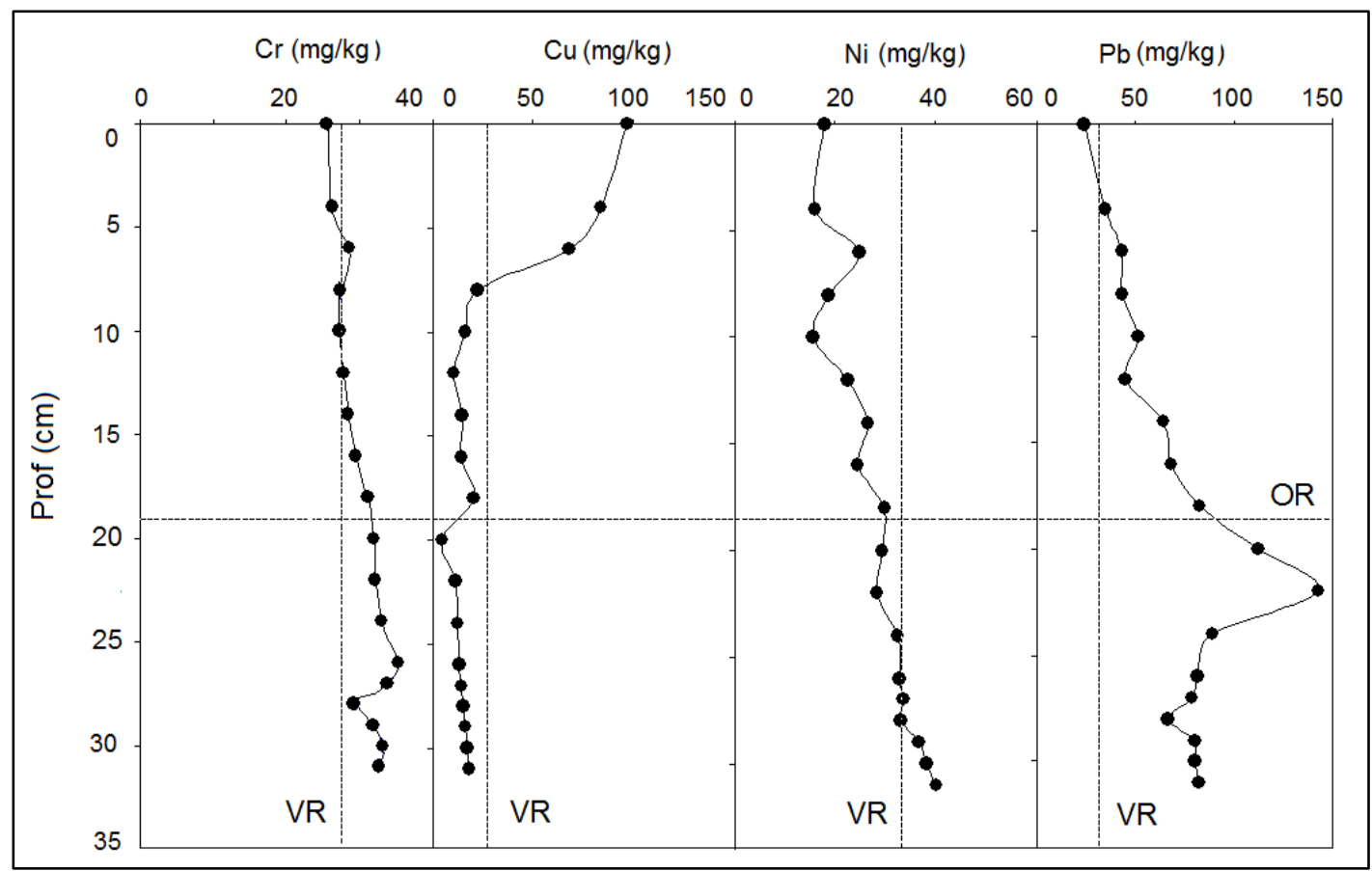

Figura 2: Perfis verticais das concentrações de cromo, cobre, níquel e chumbo no sedimento do reservatório Paiva castro, Mairiporã, SP, na zona da barragem. A linha OR indica o início da operação do reservatório. VR - Valores de Referência Regional. Modificado de Cardoso-Silva et al. (2016).

No entanto, hoje são mais expressivas ainda as quantidades de peróxido de hidrogênio aplicadas como algicida (Figura 3) nos reservatórios sob gerenciamento da SABESP. Em 2008 foram aplicadas 620 toneladas de peróxido no Guarapiranga, contra aproximadamente 350 toneladas de sulfato de cobre (CETESB, 2012). Para os reservatórios Rio Grande e Taiaçupeba, os valores de peróxido de hidrogênio aplicados também são muito mais expressivos do que os de sulfato de cobre aplicados.

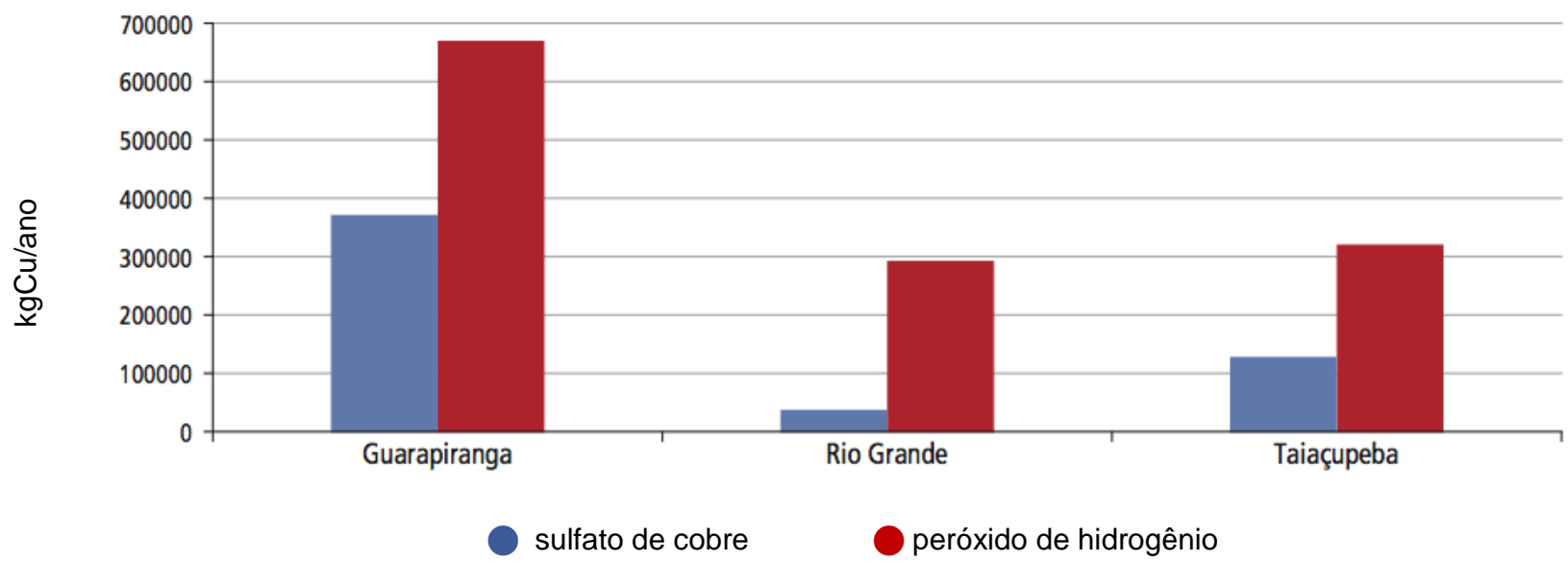

Figura 3: Algicidas sulfato de cobre e peróxido de hidrogênio aplicados nos reservatórios Guarapiranga, Rio Grande e Taiaçupeba em 2011 (dados fornecidos pela SABESP), modificado de CETESB (2012).

Em estudo recente Leal (2017) determinou-se a concentração média de cobre no sedimento do reservatório Guarapiranga, da ordem de $1,11 \mathrm{gCu} / \mathrm{kg}$ de sedimento seco, próximo ao valor citado por Hanson e Stefan (1984), de $1 \mathrm{~g} / \mathrm{kg}$. Segundo esses autores, o elevado teor de cobre presente nos sedimentos dos lagos da região de Fairmont (Minessota, EUA) foi decorrente de 25 anos de aplicações de sulfato de cobre pentahidratado. Com base nas constantes aplicações de sulfato de cobre no Guarapiranga, hoje seu sedimento superficial apresenta cerca de $80 \%$ de sua área com concentrações de cobre acima do valor de referência para toxicidade provável para a biota (LEAL, 2017), o PEL (Probable Effect Level - CCME, 2003), as áreas Bad e Very Bad da Figura 4. Mas há cerca de $45 \%$ de sua área com valores mais expressivos ainda, da ordem 
de 10 vezes acima do PEL, a área Very Bad (Figura 4). Segundo Leal (2017), considerando os valores médios levantados para a Guarapiranga, decorrente dos 43 anos de aplicações rotineiras de sulfato de cobre, pode-se inferir que o estoque desse elemento em todo o sedimento do reservatório está na casa das 4530 toneladas de $\mathrm{Cu}$ ou de 17.794 toneladas de sulfato de cobre pentahidratado aplicado, batendo a casa dos R \$ 400 milhões os recursos financeiros necessários para todo processo de compra, transporte e de aplicações por barco do sulfato de cobre no reservatório. Inclusive, já ocorreu aplicação no reservatório todo por meio de helicóptero (MANCUSO, 1987). Com base nos dados levantados por Leal (2017), estimou-se em quase R\$ 30 milhões os recursos financeiros aplicados no processo de compra e aplicações do peróxido de hidrogênio.
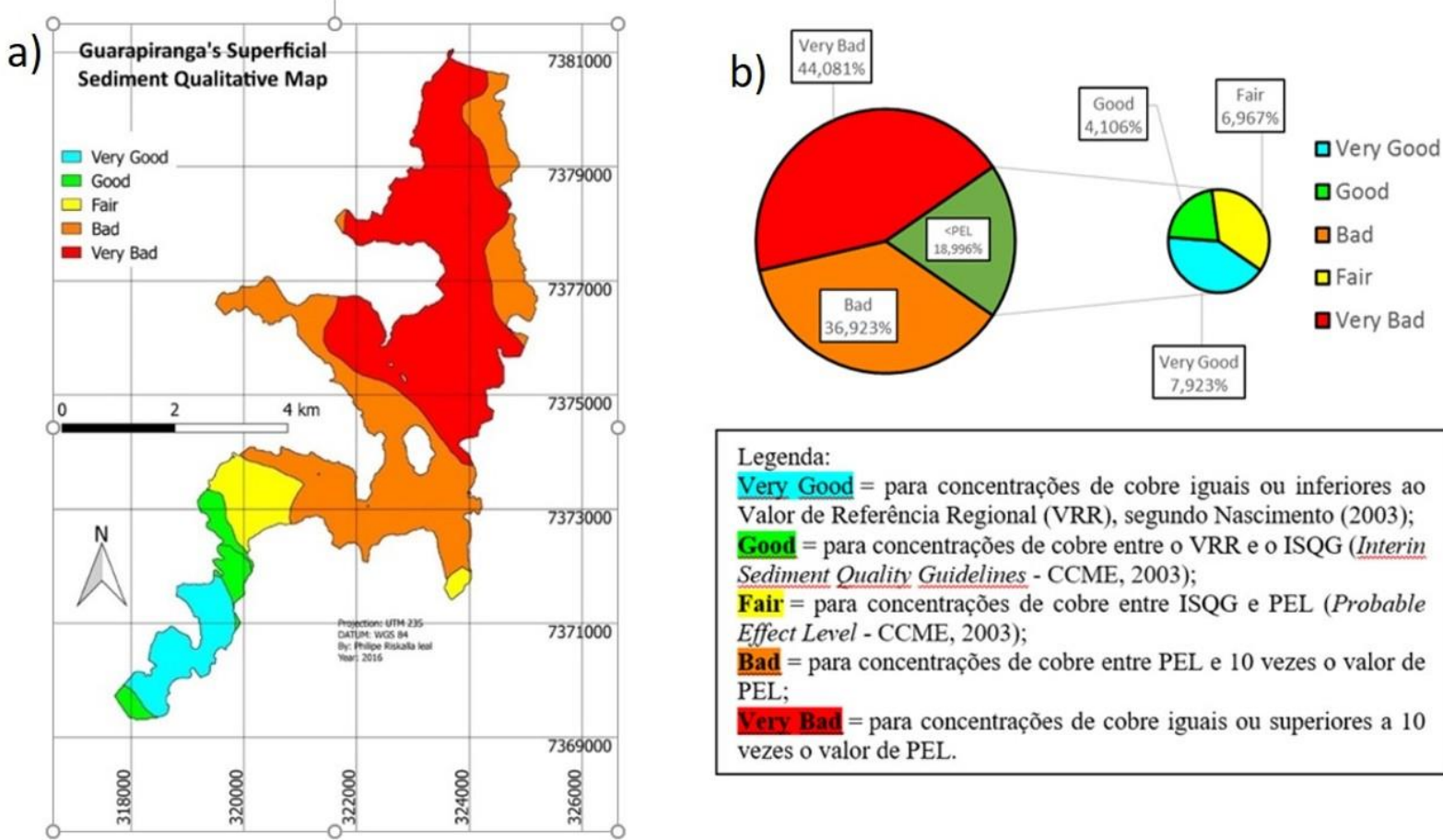

Very Good = para concentrações de cobre iguais ou inferiores ao Valor de Referência Regional (VRR), segundo Nascimento (2003); Good = para concentrações de cobre entre o VRR e o ISQG (Interin Sediment Quality Guidelines - CCME, 2003);

Fair = para concentrações de cobre entre ISQG e PEL (Probable Effect Level - CCME, 2003);

$\mathbf{B a d}=$ para concentrações de cobre entre PEL e 10 vezes o valor de PEL;

= para concentrações de cobre iguais ou superiores a 10 vezes o valor de PEL.

Figura 4: Mapa qualitativo do sedimento superficial do reservatório Guarapiranga (a), com base nos teores de cobre no sedimento. Porcentagens da distribuição espacial da qualidade do sedimento do reservatório Guarapiranga (b). Autor: Leal (2017).

O uso de sulfato de cobre para o controle do crescimento fitoplanctônico causa ruptura da célula algal e a liberação de metabólitos para a água, incluindo as cianotoxinas. Neste caso, o impacto econômico poderá aumentar, devido à necessidade de um tratamento posterior da água empregada no abastecimento público para a eliminação das substâncias dissolvidas, como pelo emprego do carvão ativado. A Portaria N. ${ }^{\circ}$ 2.914/2011 (BRASIL, 2011) discorre que o monitoramento de cianobactérias no manancial de abastecimento deve obedecer frequência mensal, quando o número de cianobactérias não exceder 10.000 células $/ \mathrm{ml}$, e semanal, quando o número de cianobactérias exceder este valor; complementada pelo Capítulo VI (§ 4o): quando a densidade de cianobactérias exceder 20.000 células $/ \mathrm{ml}$, deve-se realizar análise de cianotoxinas na água do manancial, no ponto de captação, com frequência semanal; relativo à aplicação de algicidas no Cap. VI temos (\$ 6o): em função dos riscos à saúde associados às cianotoxinas, é vedado o uso de algicidas para o controle do crescimento de microalgas e cianobactérias no manancial de abastecimento ou qualquer intervenção que provoque a lise das células; $(\S 70)$ : as autoridades ambientais e de recursos hídricos definirão a regulamentação das excepcionalidades sobre o uso de algicidas nos cursos d'água superficiais. Com a aprovação da CONAMA 467 (2015), no presente há segurança jurídica respaldando as aplicações rotineiras e não excepcionais de sulfato de cobre e de peróxido de hidrogênio.

A Limnologia, a ciência que estuda as águas interiores, e diretamente envolvida com a utilização racional e com a conservação e recuperação dos recursos hídricos, não é recente e muito menos incipiente no Brasil. Como apontado por Cardoso-Silva et al. (2013) há no Brasil as condições objetivas, com laboratórios, técnicos especializados, domínio de métodos de campo e laboratório, bem como de análise de dados, que permitem estudar os reservatórios e sua biota, e isso é mais sólido ainda principalmente no Estado de São Paulo. Com base nos múltiplos estudos executados por essa competência instalada é possível para cada 
reservatório, definir programas de monitoramento e manejo específicos para os componentes da biota, como o fitoplâncton, as cianobactérias e para as macrófitas aquáticas (POMPÊO 2017). Com base nas informações levantadas no monitoramento, de modo preventivo podem ser aplicados procedimentos de controle minimizando os eventuais impactos futuros decorrentes da explosão no crescimento indesejado do organismo e mesmo reduzir o aporte financeiro necessário para aplicar todas as etapas de controle, como apontado em Pompêo (op cit.). Mas não se pode deixar de compreender o que ocorre no entorno do reservatório, a bacia hidrográfica, e suas alterações nos usos e ocupações ao longo do tempo e no espaço, pois para melhor compreender o que se observa na massa de água ou no sedimento, por exemplo, muitas vezes a explicação e a própria solução estão fora do corpo de água (POMPÊO et al.2015; POMPÊO, 2017).

Embora o eventual uso de sulfato de cobre possa ser considerado, espera-se que unicamente em situações inesperadas de intenso crescimento, emergenciais e de uso esporádico. Mas seu uso deverá ser decorrente da impossibilidade ou do insucesso na aplicação de outros meios de controle e sua aplicação posta em prática somente após a avaliação de custo / benefício.

Há diversos aspectos que colocam em cheque a eficiência e a propriedade da continuidade da política de emprego de algicidas a base de sulfato de cobre como a principal forma de controlar o crescimento das algas no Brasil. Dentre esses aspectos, com base no exemplo do reservatório Guarapiranga, podem ser citados (POMPÊO, 2017): a continuidade dos blooms de algas e eventualmente de macrófitas aquáticas; a aplicação quase diária de algicidas, particularmente o sulfato de cobre; as grandes quantidades aplicadas; o significativo aporte financeiro necessário para o controle algal; a significativa área do sedimento com elevadas concentrações de cobre; a expressiva toxicidade potencial relativa ao cobre depositado; a possibilidade de interferir nos demais usos do sistema; o comprometimento potencial da biota não alvo; a falta de coleta e tratamento dos esgotos lançados in natura no reservatório e o prejuízo aos demais serviços ecossistêmicos já são questões mais do que suficientes para por em cheque a eficiência e a propriedade da continuidade da política de emprego de algicidas à base de sulfato de cobre como a principal forma de controlar o crescimento das algas no Brasil, e agora formalmente consolidado com a publicação da CONAMA 467.

\section{CONSIDERAÇÕES FINAIS}

Das considerações apresentadas neste manuscrito é possível compreender que se nossas águas e sedimentos dos reservatórios não se encontram em boa qualidade química ou ecológica, conforme a DQA (EC, 2000; MOSS, 2008; CARDOSO-SILVA et al.2013) é porque não há interesse na sua solução, particularmente relacionados à coleta e tratamento dos esgotos antes de seu lançamento in natura, apesar da extrema competência técnica nacional no setor. Isto sugere que os atores envolvidos nas tomadas de decisão têm outra compreensão de valores sobre os problemas a atacar. Segundo Selborne (2001), os problemas de água no mundo estão relacionados principalmente com a sua má distribuição e de conhecimento e recursos ligados a ela, não a quantidades absolutas. A meta das discussões relativas à gestão das águas, segundo esse autor, deve ser guiar o desenvolvimento por um caminho sustentável e equitativo, e os benefícios de uma determinada distribuição de água devem ser pesados contra os custos sociais e econômicos. No entanto, é errôneo depositar as esperanças na CONAMA 467, pois a forma como redigida e como provavelmente será aplicada apenas reforçará a visão corrente de não garantir a sustentabilidade ambiental e nem os serviços ecossistêmicos oferecidos pelo reservatório e seu entorno imediato. Esta Resolução apenas reforça o manejo do organismo considerado problema, num ciclo vicioso contínuo de manejos e crescimentos descontrolados recorrentes, visto não disciplinar a atuação de modo preventivo e autossustentável, optando pela coleta e o tratamento dos esgotos, os verdadeiros responsáveis pela entrada de nutrientes e pelo processo de eutrofização e do crescimento explosivo, particularmente de algas ou macrófitas aquáticas.

\section{AGRADECIMENTOS}

O autor agradece a FAPESP pelo suporte financeiro (procs. 2012/11890-4, 2014/22581-8; 2016/24528-2). 


\section{REFERÊNCIAS}

ABLIMNO, Associação Brasileira de Limnologia. Moção do XII Congresso Brasileiro de Limnologia, da Sociedade Brasileira de Limnologia, Utilização de agrotóxicos para controle de macrófitas aquáticas, 2009.

ANDRADE, A. Monitoramento e manejo de macrófitas aquáticas em reservatórios brasileiros. "Ciclo de Conferências de Gestão Ambiental", Sabesp, São Paulo, 2009.

ANGELINI, R.; BINI, LM.; STARLING, F.L.R.M. Efeitos de diferentes intervenções no processo de eutrofização do lago Paranoá (Brasília - DF). Oecologia Brasiliensis, v. 12, n. 3, p. 564-571, 2008.

ANVISA, $\quad$ F56 - $\quad$ Fluridona, sem data, disponível em http://portal.anvisa.gov.br/wps/wcm/connect/1a242e00406a88329951fb137b78f2dc/f56.pdf?MOD=AJPER ES, acessado em novembro de 2015.

BEGHELLI, F.G.S.; ROSA, A.H.; NISHIMURA, P.Y.; MEIRINHO, P.A.; LEONARDI, B.F.; GUIDUCE, F.S.; LOPEZ-DOVAL, J.C.; POMPÊO, M.; MOSCHINI-CARLOS, V. Aplicações de sulfato de cobre no reservatório Guarapiranga, SP: distribuição no meio e efeitos sobre a comunidade planctônica, In: POMPÊO, M.; MOSCHINI-CARLOS, V.; NISHIMURA, P.H.; CARDOSO-SILVA, S.; LÓPEZ-DOVAL, J.C. (Orgs.) Ecologia de reservatórios e interfaces, Instituto de Biociências - IB/USP Universidade de São Paulo, São Paulo, 2015, 460 p.

BERTI, K.A.F. Avaliação dos impactos ambientais devido ao uso de mecanismos de controle de macrófitas em reservatórios. Dissertação - Programa de Pós-Graduação em Engenharia de Energia, Itajubá, (MG), 77 p., Disponível em http://saturno.unifei.edu.br/bim/0042992.pdf, 2015, acessado em 2/08/2016.

BRASIL, Portaria MS n. 2.914/2011, MINISTÉRIO DA SAÚde, Série E. Legislação de Saúde, Brasília, DF, 2012, Disponível em http://177.153.6.85/portaria2914/theme/documentos/002.pdf

CALEFFI, S. Impacto do uso de sulfato de cobre sobre o zooplâncton na Represa Guarapiranga. In: ESPÍNDOLA, E.L.G.; PASCHOAL, C.M.R.B.; ROCHA, O.; BOHRER, M.B.C.; OLIVEIRA NETO, A.L. (Eds.). Ecotoxicologia: perspectivas para o Século XXI. São Carlos: RiMa, 2000.

CARDOSO-SILVA, S.; FERREIRA, T.; POMPÊO, M. Diretiva Quadro da Água: uma revisão crítica e a possibilidade de aplicação ao Brasil, Ambiente \& Sociedade, v.16, n.1. p. 39-58, 2013.

CARDOSO-SILVA, S.; FERREIRA, P.A.L.; MOSCHINI-CARLOS, V.; FIGUEIRA, R.C.L.; POMPÊO, M. Temporal and spatial accumulation of heavy metals in the sediments at Paiva Castro Reservoir (São Paulo, Brazil), Environmental Earth Sciences, v. 75, n. 9, p. 1-16, 2016.

CCME, Summary of existing Canadian environmental quality guidelines, Canadian sediment quality guidelines for the protection of aquatic life. Canadian Council of Ministers of the Environment, 2003.

CETESB - Companhia de Tecnologia de Saneamento Ambiental, Relatório de qualidade das águas interiores no Estado de São Paulo 2007, São Paulo: Série Relatórios, Secretaria de Estado do Meio Ambiente, 537p., 2008.

CETESB - Companhia de Tecnologia de Saneamento Ambiental, Relatório de qualidade das águas interiores no Estado de São Paulo 2005, São Paulo: Série Relatórios, Secretaria de Estado do Meio Ambiente, 488p., 2006.

CETESB - Companhia de Tecnologia de Saneamento Ambiental, Relatório de qualidade das águas interiores no Estado de São Paulo 2006, São Paulo: Série Relatórios, Secretaria de Estado do Meio Ambiente, 327p., 2007.

CETESB - Companhia de Tecnologia de Saneamento Ambiental, Relatório de qualidade das águas interiores no Estado de São Paulo 2008, São Paulo: Série Relatórios, Secretaria de Estado do Meio Ambiente, 528p., 2009.

CETESB - Companhia Ambiental do Estado de São Paulo, Relatório de qualidade das águas interiores no Estado de São Paulo 2011, São Paulo: Série Relatórios, Secretaria de Estado do Meio Ambiente, 356 p., 2012.

CONAMA - Conselho Nacional do Meio Ambiente, Ministério do Meio Ambiente, $4^{\text {a }}$ Reunião do Grupo Trabalho - 19 e 20 de março de 2009, Dispõe sobre a pesquisa, o registro, a comercialização e utilização 
de agrotóxicos em ambientes aquáticos, Versão Com Emendas, Disponível em http://www.mma.gov.br/port/conama/processos/E392D222/PropResolAgrotoxicosVSuja4Reuniao_20mar0 9.pdf

DI NINO, F., THIÉBAUT, G.; MULLER, S. Response of Elodea nuttallii (Planch.) H.St. John to manual harvesting in the North-East of France. Hydrobiologia, v. 551, p. 147-157, 2005.

EC - European Commission (2000) Directive 2000/60EC of the European Parliament and of the Council of 23 October 2000 Establishing a Framework for Community Action in the Field of Water Policy. Official Journal 22, December 2000 L 327/1. European Commission, Brussels.

FCTH, Avaliação do sistema Pinheiros-Billings com o protótipo de flotação, 82 p., sem data, acessado em 19/11/2015, disponível em http://www.emae.com.br/arquivos/internet/Projetos\%20e\%20Empreendimentos/Melhoria\%20das\%20Agua s\%20do\%20Rio\%20Pinheiros/Volume\%201\%20-\%20Sumario_.pdf.

GOLDMAN, C.R.; HORNE, A.J. Limnology. EUA, McGraw-Hill. 1983, 464p.

GUTIÉRREZ, E., HUERTO, R., SANDAÑA, P.; ARREGUÍN, F. Strategies for water hyacinth (Eichhornia crassipes) control in México. Hydrobiologia, v. 340, p. 181-185, 1996.

HANSON, M.J.; STEFAN, H.G. Side effects of 58 years of copper sulfate treatment of the Fairmont Lakes, Minnesota, Water Resources Bulletin, v. 20, n. 6, p. 889-900, 1984.

HENDERSON-SELLERS, B.; MARKLAND, H.Z. Decaying lakes: the origins and control of cultural eutrofication. New York, Wiley. 1987, 254 p.

KAKINAMI, S.H.; SANTOS, A.I.P.; MENDES, R.A.P.; ALVIM, S.C. Rio Pinheiros: suas águas e suas margens. p. 191-223. In: ROMÉRO, M.A., PHILIPPI JR., A.; BRUNA, G.C. (eds.) Panorama ambiental da Metrópole de São Paulo. São Paulo: USP/Signus Editora, 2004, 584p.

LEAL, P.R. Geoestatística e ecotoxicidade como ferramentas para gestão de reservatórios. Estudo de caso: reservatório Guarapiranga (São Paulo, BR). 2017. 133p., Dissertação (Mestrado) - Instituto de Biociências, Universidade de São Paulo, São Paulo, 2017.

MANCUSO, C.S. Controle do desenvolvimento de algas em águas de abastecimento público, Revista DAE, v. 47, n. 149, p. 151-156, 1987.

MARIANI, C.F. Variação temporal do teor de SVA/ MES e avaliação integrada do sedimento do Braço do Rio Grande (Complexo Billings - SP), Tese (Doutorado) - Instituto de Biociências da Universidade de São Paulo. Departamento de Ecologia, 143 p., 2010.

MARIANI, C.F.; POMPÊO, M. Potentially bioavailable metals in sediment from a tropical polymictic environment Rio Grande Reservoir, Brazil. Journal of Soils and Sediments, v. 8. p. 284-288, 2008.

MOSS, B. The Water Framework Directive: total environment or political compromise? Science of the Total Enviormental, v. 400, n. 1-3, p. 32-41, 2008.

POMPÊO, M. As macrófitas aquáticas em reservatórios tropicais: aspectos ecológicos e propostas de monitoramento. In: M.L.M. Pompêo, Perspectivas da limnologia no Brasil. São Luís: Gráfica e Editora União, 191 p., 1999.

POMPÊO, M. Monitoramento e manejo de macrófitas aquáticas, Oecologia Brasiliensis, v. 12, n. 3, p. 406424, 2008.

POMPÊO, M. Monitoramento e manejo de macrófitas aquáticas em reservatórios tropicais brasileiros, São Paulo; Instituto de Biociências da USP, 2017. 138 p., Disponível em http://www.ecologia.ib.usp.br/portal/macrofitas/.

POMPÊO, M. O Conama e o uso de agrotóxicos em ambientes aquáticos, Correio da Cidadania, 13/04/2009, acessado em 15 de maio de 2016.

POMPÊO, M.; KAWAMURA, K.; MOSCHINI-CARLOS, V.; CARDOSO-SILVA, S.; LOBO, F.L.; MEIRINHO, P.A.; BITENCOURT, M.D.; MEIRELLES, S.T. Heterogeneidade espacial horizontal da qualidade da água no reservatório Rio Grande, Complexo Billings, São Paulo, Brasil, In: POMPÊO, M.; MOSCHINI-CARLOS, V.; NISHIMURA, P.H.; CARDOSO-SILVA, S.; LÓPEZ-DOVAL, J.C. (Orgs.) Ecologia de reservatórios e interfaces, Instituto de Biociências - IB/USP Universidade de São Paulo, São Paulo, 2015, 460 p. 
POMPÊO, M.; MOSCHINI-CARLOS, V. O abastecimento de água e o esgotamento sanitário: propostas para minimizar os problemas no Brasil. In: ROSA, A.H.; FRACETO, L.F.; MOSCHINI-CARLOS, V. (Org.). Meio ambiente e sustentabilidade. Porto Alegre: Bookman Companhia Editora, 410 p., 2012.

POMPÊO, M.; MOSCHINI-CARLOS, V. Prefácio, pgs. v a vii, In: POMPÊO, M.; MOSCHINI-CARLOS, V.; NISHIMURA, P.H.; CARDOSO-SILVA, S.; LÓPEZ-DOVAL, J.C. (Orgs.) Ecologia de reservatórios e interfaces, Instituto de Biociências - IB/USP Universidade de São Paulo, São Paulo, 2015, 460 p.

POMPÊO, M.; PADIAL, P.R.; MARIANI, C.F.; SILVA, S.C.; MOSCHINI-CARLOS, V., SILVA, D.C.V.R.; PAIVA, T.C.B.; BRANDIMARTE, A.L. Biodisponibilidade de metais no sedimento de um reservatório tropical urbano (reservatório Guarapiranga, São Paulo, Brasil): há toxicidade potencial e heterogeneidade espacial? Geochimica Brasiliensis, v. 27, n. 2, p. 104-119, 2013.

RAMAN, R.K.; COOK, B.C. Guidelines for applying copper sulfate as an algicide: Lake Loami field study. Illinois Department of Energy and Natural Resources Office of Research and Planning, 1988, 96p., acessado em novembro de 2015, disponível em http://www.isws.illinois.edu/pubdoc/CR/ISWSCR-450.pdf

RESOLUÇÃO CONAMA n. 274, de 29 de novembro de 2000, Publicada no DOU n. 18, de 25 de janeiro de 2001, Seção 1, p. 70-71,

RESOLUÇÃO CONAMA n. 357, de 17 de março de 2005, Publicada no DOU no 053, de 18/03/2005, p. 5863 ,

RESOLUÇÃO CONAMA n. 467, de 17 de julho de 2015, Publicada no DOU no 135, seção 1, p. 70 a 71. Disponível em http://www.mma.gov.br/port/conama/legiabre.cfm?codlegi=712, acessada em 29 de setembro de 2015.

ROCHA, S.M.; PIVELI, R.P.; ROCHA, A.A. Organismos bentônicos indicadores na represa do Guarapiranga - SP - Brasil, Departamento de Saúde Ambiental, da Faculdade de Saúde Pública, da Universidade de São Paulo, sem data, acessado em novembro de 2015.

SELBORNE, L. A ética do uso da água doce: um levantamento. Brasília: UNESCO, 2001. 80p.

STRAŠKRABA, M.; TUNDISI, J.G. Gerenciamento da qualidade da água de represas. Tradução Dino Vannucci. São Carlos: International Lake Environmental Committee. 280 p., Série Diretrizes para o Gerenciamento de Lagos, v. 9, 2000.

VALLENTYNE, J.R. Introducción a la limnología - los lagos y el hombre. Barcelona: Omega. 1978, $169 \mathrm{p}$. 